\title{
Why Study on a MOOC? The Motives of Students and Professionals
}



\begin{abstract}
Massive Open Online Courses have emerged as a popular mechanism for independent learners to acquire new knowledge and skills; however, the challenge of learning online without dedicated tutor support requires learners to self-motivate. This study explores the primary motivations reported by participants in two MOOCs: Fundamentals of Clinical Trials and Introduction to Data Science $(n=970)$. Each MOOC drew a diverse cohort of participants ranging from professionals working in the field to students preparing to enter it. Across both MOOCs, a similar profile of primary motivations emerged, with respondents identifying the potential benefits to their current role, or future career, alongside more general responses reflecting casual interest in the topic or a simple desire to learn. Professionals were primarily motivated by current needs, describing how the course could fill gaps in their formal knowledge, broaden their skillset to increase their effectiveness at work, or enable them to innovate. Professionals also saw the benefit of MOOC study in preparing them for new roles and career progression. Students, meanwhile, used MOOC study to complement their other learning. It is clear that MOOC study represents a popular mechanism for professionals to address both current and future learning needs.
\end{abstract}

Keywords: MOOCs, professional development, motivation

\section{Introduction}

As knowledge worker roles become more specialised and autonomous, and learning for work becomes continual and personalised, individuals must take greater responsibility for their own learning, managing their short- and long-term learning needs accordingly (Littlejohn \& Margaryan, 2014). For today's professionals, learning for work often blends deliberate, formalised learning with reactive, non-formal learning (Eraut, 2000). Formal learning opportunities may be provided through in-house training, professional bodies, or educational institutions, with costs borne by the individual or their employer. However, time and financial commitments can present barriers to learning in this way. Massive Open Online Courses (MOOCs) have emerged as a popular mechanism for individuals to 
acquire new knowledge and skills, and hold much promise for professional learning (Heller, 2014). Professionals can take advantage of the flexible delivery and zero cost of MOOCs to meet their learning needs if they do not require formal accreditation, but the price of this flexibility is that MOOCs offer little or no tutor support and require the learner to self-motivate; driving their participation and engagement in the face of other demands, including their professional role. This study explores the motivations of learners participating in two MOOCs, focused on clinical trials $(n=303)$ and data science $(n=667)$, and provides an insight into these learners' perceptions of their short- and long-term workplace learning needs and the roles that MOOCs can play in fulfilling them. The paper begins with a short review of current research on MOOCs, focusing specifically on studies that have explored motivation. This review is followed by a description of the method and context of the two courses under study, and the analysis undertaken. The results are then presented and discussed. The paper concludes with a summary of the main findings and implications, alongside a reflection on the limitations of the study and prospects for future research.

\section{Review}

In recent years, Massive Open Online Courses (MOOCs) have emerged as a key mechanism for millions of learners to access semi-formal learning opportunities, particularly those for whom this has previously been impossible because of constraints of cost or geography. The term MOOC was coined to refer to experimental formats for open online courses explored by George Siemens and colleagues in Canada in 2008 (and after) that typically drew a few thousand learners. More recently, commercial providers, such as edX, Coursera, and FutureLearn have emerged, working in partnership with universities to provide open online courses that scale to tens of thousands of participants. These courses foreground content presentation, typically lecture, video, and automated assessment, over opportunities for interaction (Anderson, 2013; Margaryan, Bianco, \& Littlejohn, 2015), While these scalable designs have led some authors to question their utility as an effective environment for online learning (Rhoads, Berdan, \& Toven-Lindsey, 2013), their popularity is clear. Demographic data provided by MOOC providers suggest that at least two-thirds of MOOC participants are already highly educated (at least to college level) (edX, 2014). These individuals value access to free learning content, and are undeterred by the absence of formal accreditation. Unlike traditional HE courses, where learner motivations are largely standardised (for example successful completion of a course or degree programme as a marker of success), the diversity of learners in a MOOC results in a range of motivations for participation (Kizilcec, Piech, \& Schneider, 2013) and potentially leads to different levels of engagement (Milligan, Littlejohn, \& Margaryan, 2013) which may not be focused on completion (Breslow et al., 2013). To understand learning in MOOCs it is necessary to more fully investigate the particular motivations and drivers that influence individual learner's behaviour and actions during MOOC study (Gašević, Kovanović, Joksimović, \& Siemens, 2014).

If MOOC learners are not motivated by completion, then what does motivate them? Several studies have attempted to understand the nature of MOOC motivation. Zheng, Rosson, Shih, and Carroll (2015) conducted interviews with learners who had undertaken a variety of MOOCs and identified four categories of MOOC learner motivation: fulfilling current needs, preparing for the future, satisfying curiosity, and connecting with people. Their findings suggest that completion is just one outcome of MOOC participation, with key motivations to study being intrinsic in nature, related 
primarily to personal improvement. In a larger, survey-based study, exploring motivations of MOOC learners based in the United Kingdom, Spain, and Syria, seven different types of motivation were identified (White, Davis, Dickens, Leon, \& Sanchez-Vera, 2015), mirroring the categories identified by the Zheng et al. (2015) study, and in addition identifying categories of motivation reflecting other extrinsic factors: the free and open nature of MOOCs, their convenience, and the prestige of courses run by high-quality institutions. Exploring aspects of motivation to learn in detail, de Barba, Kennedy, and Ainley (2016) investigated the link between motivation and performance in MOOCs, drawing on theories of motivation such as Hidi and Renninger's (2006) four phase Model of Interest Development, Wigfield and Eccles' (1992) Expectancy-Value Theory of Motivation and Ames' (1992) Achievement Goal Theory. The de Barba study explored a range of intrinsic motivations, including individual and situational interest (overarching interest, and the transient motivation that comes from a stimulating environment or task), achievement goals (whether individuals adopted a mastery or performance goal driven approach), and value beliefs (why learners believe a task is valuable to them). Their study highlighted the key role that motivation, and in particular situational interest, plays in influencing MOOC participation and performance.

There is growing evidence that MOOCs are being used by workers for their self-directed learning: in a study of 32 MOOCs, Christensen et al., (2013) noted that $44 \%$ of respondents cited "Gain specific skills to do my job better" when asked to choose reasons for studying. MOOCs therefore look set to play a key role in the professional learning of knowledge workers in the coming years. Several studies, such as Salmon, Gregory, Lokuge Dona, and Ross, B. (2015) have explored the use of MOOCs for professional development in education, but studies that explore the motivations of professionals utilising MOOCs to develop their knowledge in other professional domains are absent. While the studies described above have provided some insight into the motivations of MOOC learners in a broad range of MOOCs, this study focuses on MOOCs that appeal to a specialised, professional (or preprofessional) audience and attempts to further our understanding of why these learners choose MOOC study and how they are perceived to fulfil workplace learning needs and provide preparation for future careers.

\section{Method and Analysis}

The study draws on data collected during two parallel studies exploring the MOOC learning experiences of professionals. Data was collected between late 2013 and mid-2014. The MOOCs selected for inclusion in the study were courses whose topic was likely to appeal to a professional audience. We anticipate that this audience was seeking to update or supplement their professional skills or to gain a certificate in a topic as evidence of their knowledge rather than taking the MOOC simply for entertainment. The Introduction to Data Science MOOC (IDS: https://www.coursera.org/course/datasci) from the University of Washington was an eight-week course offered on the Coursera platform, suited to those with intermediate-level programming experience. Fifty thousand learners from 197 countries enrolled in the MOOC. The Fundamentals of Clinical Trials MOOC (FCT: https://www.edX.org/course/harvard-university/hsphhms214x/fundamentals-clinical-trials/941) offered by edX and developed by Harvard Medical School, provided an introduction to the research designs, statistical approaches, and ethical considerations of clinical trials, aimed at health professionals and those studying for a health professional role. The 
course attracted 22,000 registrants from 168 countries. MOOCs suffer high drop-out rates, and at the time of data collection (part-way through the courses), it is likely that less than one quarter of the participants (12,500 and 6,500 for these two courses) would be active (Weller, 2014). Through liaison with course teams, a message posted to the course platform invited learners to participate in the studies (see Littlejohn, Hood, Milligan, \& Mustain, 2016; Milligan \& Littlejohn, 2014; and Milligan \& Littlejohn, 2016 for full details) by completing an online survey instrument. The survey instrument was designed to provide a measure of the MOOC participants' ability to self-regulate their learning (adapted from Fontana, Milligan, Littlejohn, \& Margaryan, 2015),), along with demographic information and additional open-ended questions exploring learner motivation and expectations. Respondents were asked to indicate whether they were currently employed as a professional in a field relevant to the course topic, or whether they were studying towards a qualification in a related field. Ethical standards were adopted according to local regulations, and participants were free to withdraw from the study at any point without prejudice.

This study focuses on responses to one open-ended question: What was your primary motivation for taking this course? For the Introduction to Data Science (IDS) course, this comprised 667 valid responses (5.3\% active participants) and for the FCT course, 303 valid responses (4.7\% of active participants). Responses to the data from the FCT course were categorised by one researcher according to an emergent coding scheme. The scheme was refined in discussion with a second researcher and all responses were then reclassified using the refined coding scheme by a third researcher. Inter-rater reliability was high with initial agreement rate exceeding 93\%. Discrepancies were reviewed and responses re-classified as necessary. The codes generated are described in the Results section below. While the question asked for "primary motivation," the survey instrument utilised free text entry for this question and a small number of respondents reported more than one motivation. These additional responses were recorded, but discarded from the analysis reported here. The discarded responses did not represent any new category of response beyond those already included in the coding scheme. The codes identified in this analysis were then used to classify data from the IDS course. Only one additional category emerged, represented by a single instance. Quotes presented in the text are drawn from the FCT course. Quantitative data analysis was carried out using the IBM software package SPSS v22.

\section{Results}

Learner motivations were explored through the open-ended question: What was your primary motivation for taking this course? We identified nine types of motivation for participating in the two MOOCs. Motivations reported fell into two overarching categories. The great majority of responses made reference to the topic of the course (four categories, coded as: general interest in the topic, the opportunity to learn about the topic, the relevance of the course topic to current role challenges, and its relevance to future career intention). A much smaller group of responses focused on the course as an entity (five categories, coded as: the prestige of the MOOC provider, the opportunity to study on a $M O O C$, the opportunity to obtain a certificate of learning, the (zero) cost of participation, and the course delivery language). The second group of responses was combined into an other motivation category for this analysis. These motivation types are presented below, and in Table 1. 
Table 1

MOOC Participant Motivations

\begin{tabular}{|c|c|c|c|}
\hline Category & $\begin{array}{c}\text { FCT } \\
\mathrm{n}(\%), \text { rank }\end{array}$ & $\begin{array}{c}\text { IDS } \\
\mathrm{n}(\%), \text { rank }\end{array}$ & $\begin{array}{l}\text { COMBINED } \\
\text { n (\%) }\end{array}$ \\
\hline Relevance to current role & $97(32.0 \%) 1$ & $151(22.6 \%) 3$ & $248(25.6 \%)$ \\
\hline Learning content & $82(27.1 \%) 2$ & $227(34.0 \%) 1$ & $309(31.9 \%)$ \\
\hline Relevance to future career & $50(16.5 \%) 3$ & $113(16.9 \%) 4$ & $163(16.8 \%)$ \\
\hline Interest in the topic & $47(15.5 \%) 4$ & $160(24.0) 2$ & $207(21.3 \%)$ \\
\hline $\begin{array}{l}\text { Other motivation (prestige, certification, } \\
\text { MOOC study, (zero) cost, opportunity to } \\
\text { learn in English. }\end{array}$ & $27(8.9 \%) 5$ & $16(2.5 \%) 5$ & $43(4.4 \%)$ \\
\hline Total & 303 & 667 & 970 \\
\hline
\end{tabular}

The smaller, second group of responses (43/970, 4.4\%) described motivations that focused not on the learning content, but on the course as an entity. Some participants $(20 / 303,6.6 \%$ for FCT, and 5/667, $0.8 \%$ for IDS) were motivated by the prestige of the MOOC provider. This was particularly the case for the FCT MOOC which was offered by the Harvard Medical School. Similarly, a small number, exclusively from the FCT course $(5 / 303 ; 1.66 \%)$, identified the opportunity to obtain a course certificate as their primary motivation. A few individuals reported that they wanted to experience learning on a MOOC, while others were attracted by the zero cost associated with study or the opportunity to learn in English. While all motivations are of interest, the focus of our study is on those who saw MOOCs as a source of learning, and these motivations will not be discussed further. In this study, in contrast to the MOOCs studied by Zheng et al. (2015), none of the respondents across either group cited connecting with other people as a primary motivation to learn in the MOOC.

The great majority of motivations reported were focused around the learning potential offered by the courses. For some (207/970, 21.3\% of the combined sample), responses indicated an Interest in the course content but did not articulate any need to learn. Sample responses in this category included "I'm interested in this theme" and "my keen interest in the subject." These participants appear to be focused on learning as a pastime and this category corresponds to the MOOCs as Edutainment category identified by Zheng et al. (2015). A second category, representing around one third of responses (309/970, 31.9\% of combined sample) described motivations focused on the Learning opportunities provided by the MOOC, but did not relate their learning to any wider goal. For some, responses were little more than general statements of intention to learn such as one respondent whose motivation was "the knowledge that I would acquire." Other respondents were able to articulate a more specific motive, for example: "I wanted to learn to interpret clinical trials." Responses in this category often reflected the overall course objectives and perhaps reflect participants' desire to broaden their domain knowledge, or supplement other learning. A third category representing around a quarter of participants (248/970, 25.6\% of combined sample) included those responses that made an explicit link between the course content and an individual's current role. Again, there was a range 
of responses from the general "Fill a knowledge gap related to my professional work" to more detailed descriptions of the perceived value of the course such as "I am working currently in testing software for clinical trials and want to understand the basics" or "I'm currently designing a Phase 1 trial that will assess the validity of a psychological intervention on a specific medical population. I am designing the study intervention and writing the Health and Safety Plan while taking the course." The specific motivations reported in this category demonstrate how individuals were explicitly using MOOCs as a mechanism to improve their current work practice. Together, these two categories reflect the fulfilling current needs category defined by Zheng et al. (2015) with this classification seeking to differentiate between personal motivation and motivation focused on role. A fourth category of responses (163/970, 16.8\%) made a similar link to role but focused on the future, providing an insight into how MOOC participants saw the courses as helping to prepare for a future career move, equivalent to the category of preparing for the future identified by Zheng et al. (2015). Again, responses varied from the general "Advance my career" and "Helpful for a future job" to the more specific "I am a biostatistician thinking about a career re-orientation in the field of clinical trials" and "I want to move from basic laboratory research into industry ... this course offers me a possibility to move into new career path." These four primary motivation types, accounting for over $95 \%$ of the combined sample, provide some insight into how learners perceive the learning value of MOOCs. Together, more than 4 in 10 participants $(411 / 970,42.4 \%)$ were motivated, not just to learn, but expressed an extrinsic motivation that linked their learning to either their current or future role.

The relative distribution of motivations differs markedly between the two courses $\left(\chi^{2}(4, N=970)=\right.$ $37.31, \mathrm{p}<$.0001), with relevance to current role most important for those studying FCT and learning opportunities provided by the course perceived as most important for most IDS participants. The different pattern of motivations is to be expected, while both courses were selected as likely to draw an audience focused on learning for work, the content focus, educational level and pedagogic design of the two MOOCs are not matched. Each of these factors is likely to impact learner's perception of the value of the course and alternative study designs, for example matching courses with similar pedagogical designs, would be needed to explore these relationships further.

\section{Comparison of Students and Professionals}

The survey instrument allows us to explore one factor that might influence motivation in detail: whether the participant is still a student or already working as a professional. In both studies, participants were first asked whether they were studying toward a higher education qualification in the topic of the course, and then asked whether they were working as a professional in the field. For each question, participants could answer yes or no. Participants could answer yes to both questions (for example if they were studying medicine and undertaking a residency). Removing data for this group, as well as those who answered no to each question (who were presumably undertaking the course purely for pleasure), we can explore the motivations of the student and professional cohorts in each course as shown in Table 2.

Table 2

MOOC Participant Motivations, by Current Status

\begin{tabular}{|c|c|c|c|c|c|c|}
\hline & & $\mathrm{CT}$ & & DS & $\mathrm{COI}$ & SINED \\
\hline Category & Student & Professional & Student & Professional & Student & \\
\hline
\end{tabular}




\begin{tabular}{|c|c|c|c|c|c|c|}
\hline & $\begin{array}{c}\text { n (\%), } \\
\text { rank }\end{array}$ & n (\%), rank & $\begin{array}{l}\text { n (\%), } \\
\text { rank }\end{array}$ & n (\%), rank & n (\%) & n (\%) \\
\hline $\begin{array}{l}\text { Interest in the } \\
\text { topic }\end{array}$ & $\begin{array}{r}6(15 \cdot 4 \%) \\
3=\end{array}$ & $17(14.2 \%) 3$ & $\begin{array}{r}28 \\
(24.6 \%) 2\end{array}$ & $49(18.6 \%) 3$ & $\begin{array}{r}34 \\
(22.2 \%)\end{array}$ & $66(17.2 \%)$ \\
\hline Learning content & $\begin{array}{r}15 \\
(38.4 \%) 1\end{array}$ & $\begin{array}{r}29(24.2 \%) \\
2\end{array}$ & $\begin{array}{r}64 \\
(56.1 \%) 1\end{array}$ & $56(21.2 \%) 2$ & $79(51.6 \%)$ & $85(22.1 \%)$ \\
\hline $\begin{array}{l}\text { Relevance to } \\
\text { current role }\end{array}$ & $\begin{array}{r}6(15 \cdot 4 \%) \\
3=\end{array}$ & $\begin{array}{r}46(38.3 \%) \\
1\end{array}$ & $\begin{array}{r}0(0.0 \%) \\
4=\end{array}$ & $\begin{array}{r}117(44.3 \%) \\
1\end{array}$ & $6(3.9 \%)$ & $163(42.4 \%)$ \\
\hline Future Career & $\begin{array}{r}9(26.5 \%) \\
2\end{array}$ & $13(10.8 \%) 5$ & $\begin{array}{r}22 \\
(19.3 \%) 3\end{array}$ & $36(13.6 \%) 4$ & $31(20.3 \%)$ & $49(12.8 \%)$ \\
\hline Other motive & $3(7.7 \%) 5$ & $15(12.5 \%) 4$ & $\begin{array}{r}0(0.0 \%) \\
4=\end{array}$ & $6(2.3 \%) 5$ & $3(2.0 \%)$ & $21(5.5 \%)$ \\
\hline Total & 39 & 120 & 114 & 264 & 153 & 384 \\
\hline
\end{tabular}

For those who identified as students, the most popular primary motivation across both courses was learning content with around half (56.1\% of IDS and $38.4 \%$ of FCT) who identified as students citing this category as their primary motivation. This group appear to be supplementing or complementing their formal learning with an additional authoritative source, as illustrated by the following responses. Sometimes they were following their individual interest "I took a paper related to clinical trial and ended up wanting to know more about the clinical trials," while for others, the MOOC materials filled a gap "to learn content that I am not exposed to at my university," while a third group appeared to be using the MOOC as a study aid: "Having the material being presented from a different source." A further $20 \%$ of the student group (19.3\% of IDS and $26.5 \%$ of FCT) indicated benefit to future career as their primary motivation. Again, responses give an indication of intent: One student responded "It is useful for my later study and work," while another highlighted "the possibility of acquiring new medical skills that could be useful for me in the future."

For both courses, students (19.3\% of IDS, $26.5 \%$ of FCT) were more likely to cite benefit to future career than professionals (13.6\% of IDS, $10.8 \%$ of FCT). It appears that benefit to future career is not as significant a motivating factor for professionals who are already working in the field. Instead, for professionals it is relevance to current role that is the most important motivation, cited by more than $40 \%$ (44.3\% of IDS, $38.3 \%$ of FCT) of professionals. For some, the course provided essential professional development: "evidence based dentistry is very new, and I never learned it in my dental school in Egypt, but it is paramount now." Among professionals, around 20\% of the group $(21.2 \%$ of IDS and $24.2 \%$ of FCT) cited learning content as their primary motivation. Here, the course presented an opportunity to explore new topics that had not been part of their own formal education: "to learn more about the design and analysis of clinical trials. As an epidemiologist most of my training has been more focused on observational studies." Others used the course to check and assure their knowledge: "to increase my understanding of clinical trials and discover whether my knowledge base was complete or lacking in information." The differing distributions of primary motivations are constant across both courses, though the small numbers of students in the FCT course make robust comparisons difficult. 


\section{Conclusion}

The analysis presented here helps us to recognize the range of motivations to learn perceived by MOOC participants. Across both of these MOOCs, which focused on technical topics with little mass appeal, a similar profile of primary motivations emerged. Respondents linked their learning to the potential benefits to their current role, or future career, alongside more general responses reflecting casual interest in the topic or a simple desire to learn. Both courses drew a significant proportion of learners seeking to learn for their own entertainment, without significant extrinsic motive; however, the majority of respondents did have a clear intention to learn. For students, studying towards a career, the courses complemented their formal study or helped them to broaden their focus to prepare themselves for their future role. On the other hand, professionals were primarily motivated by current or emerging needs, describing how the course could fill gaps in their formal knowledge, broaden their skillset to increase their effectiveness at work, or enable them to innovate. Professionals saw the benefit of MOOC study in preparing them for new roles, and career progression, though to a lesser extent than for current challenges. MOOC study appears to be driven by personal motivation: there was no evidence of MOOC study being formally linked to organisational learning and development activity. Similarly, none of the professionals made reference to other formal or semi-formal learning or training that they were undertaking; in this study, MOOCs appear to be the primary mechanism these individuals are using to fulfil their development needs. The range of motivations identified matches well with those identified by previous studies (Zheng et al., 2015; White et al., 2015) with only Zheng et al.'s (2015) connecting with other people category being absent from the motivations collected here. The content-focused categories here (general interest in the topic, the opportunity to learn about the topic, the relevance of the course topic to current role challenges, and its relevance to future career intention) allows us to differentiate different levels of engagement that directly relate to how the learners expected to utilize their new knowledge they expected to acquire.

The findings highlight the complex mix of motivations present in massive courses. The overwhelming majority of participants were focused on the learning content, and only a tiny fraction of participants cited completion or certification as their primary motivation. In these courses, the individuals appear to be intrinsically motivated - either through individual interest (Hidi \& Renninger, 2006) in the topic, or through the utility value of the learning content to other aspects of their lives (Wigfield \& Eccles, 1992). MOOC courses accommodate these differing motivations, but they do little to support them. Learners exist in isolation, unaware of other learners with similar goals and expectations. By recognizing the different types of motivation that learners bring to their study, MOOC providers could tailor the learning experience, providing different content choices and routes through the course. An individual motivated by interest may prefer a straightforward presentation of content, while those motivated by relevance to current work could be given tasks that draw on their own workplace challenges (Littlejohn \& Milligan, 2015). Learners motivated by relevance to future career may benefit from learning content that explored the real world application of knowledge. The study provides evidence that a significant proportion of learners are using these MOOCs to directly address workplace learning needs. They may wish to formalize their existing knowledge, update their professional knowledge, or respond to role change. These MOOC courses appear to be their principal source of that learning. Future studies could explore these motivations in more detail to determine whether this approach is influenced by other factors such as the availability of other training opportunities, or other individual and social factors. 
While this study has provided a clear insight into the motivations of the learners on these two courses, it is not without its limitations. As the study was exploratory in nature, we chose to use open-ended questions to collect motivations. The great majority of motivations identified fell into a limited number of categories. Future studies could utilise closed questions to more reliably record motivations, though it is still important to allow learners to suggest novel motivations. Despite being asked to report only their primary motivation, a small minority of respondents provided more than one motivation. While for this study, these additional motivations were discarded, a future study could combine the use of closed response questions with a ranking question, which captures additional motivations to develop our understanding of how different motives interact. In this study, two contexts were explored. While this allows some limited analysis of commonalities and generalizability of findings, far more courses would need to be explored before clear and predictable patterns can be recognized. As stated above, studying multiple MOOCs of similar type (e.g., same pedagogical design, or same educational level and similar topics) would reduce variation and allow a clearer picture of the importance of motivations to emerge. Lastly, the data collected here is somewhat isolated. Future studies could seek to combine data on motivations with clickstream data such as forum use, content access, and final mark. This would enable further analysis to explore the interrelationships between motivation, engagement, and persistence.

For professionals (and those about to embark upon their career) in the domains covered by this study, it is clear that MOOC study, despite its limitations, represents a popular mechanism for addressing both current and anticipated learning needs. While other studies have looked at how employers view MOOCs (Radford et al., 2014), their value for workplace learning from a learner's perspective is under-researched. Further research is needed to determine what other professional development opportunities were available to these learners, why they chose to fulfil their learning needs with MOOCs, and whether MOOC study was effective in fulfilling their needs.

\section{Acknowledgements}

This work was supported by the Bill and Melinda Gates Foundation under Grant number OPP1078781. We are grateful to Obiagele Ukadike and Nabeel Gillani for their help in facilitating our study and Dr Donatella Persico and Lou McGill for their helpful contribution to data analysis.

\section{References}

Ames, C. (1992). Classrooms: Goals, structures, and student motivation. Journal of Educational Psychology, 84(3), 261-271. DOI: http://doi.org/10.1037/oo22-0663.84.3.261

Anderson, T. (2013). Promise and/or peril: MOOCs and open and distance education [PDF Report]. Retrieved from http://www.ethicalforum.be/sites/default/files/MOOCsPromisePeril.pdf

de Barba, P.G., Kennedy, G.E., \& Ainley, M.D. (2016). The role of students motivation and participation in predicting performance in a MOOC. Journal of Computer Assisted Learning, 32(3), 218-231. DOI: http://doi.org/10.1111/jcal.12130 
Breslow, L., Pritchard, D. E., DeBoer, J., Stump, G. S., Ho, A. D., \& Seaton, D. T. (2013). Studying learning in the worldwide classroom: Research into edX's first MOOC. Journal of Research \& Practice in Assessment, 8, 13-25.

Christensen, G., Steinmetz, A., Alcorn, B., Bennett, A., Woods, D., \& Emanuel, E. J. (2013). The MOOC phenomenon: Who takes massive open online courses and why? Philadelphia: University of Pennsylvania.

edX (2014). How to bring less educated learners to MOOCs [Blog post]. Retrieved from http://blog.edx.org/how-bring-less-educated-learners-moocs

Eraut, M. (2000). Non-formal learning and tacit knowledge in professional work. British Journal of Educational Psychology, 7o, 113-136. DOI: http://doi.org/10.1348/o00709900158001

Fontana, R.P., Milligan, C., Littlejohn, A., \& Margaryan, A. (2015). Measuring self-regulated learning in the workplace. International Journal of Training and Development, 19(1), 32-52. DOI: http://doi.org/10.1111/ijtd.12046

Gašević, D., Kovanović, V., Joksimović, S., \& Siemens, G. (2014). Where is research on massive open online courses headed? A data analysis of the MOOC research initiative. International Review of Research in Open and Distance Learning, 15(5), 134-176. DOI: http://dx.doi.org/10.19173/irrodl.v15i5.1954

Heller, R.F. (2014). Learning by MOOC or by crook. Medical Journal of Australia, 200(4), 192-193. DOI: http://dx.doi.org/10.5694/mja14.00129

Hidi, S., \& Renninger, K.A. (2006). The four phase model of interest development. Educational Psychologist 41, 111-127. DOI: http://dx.doi.org/10.1207/s15326985ep4102_4

Kizilcec, R. F., Piech, C., \& Schneider, E. (2013). Deconstructing disengagement: Analyzing learner subpopulations in massive open online courses. In Proceedings of the 3rd International Conference on Learning Analytics and Knowledge (pp. 170-179). New York, NY, USA: ACM. doi: http://dx.doi.org/10.1145/2460296.2460330

Littlejohn, A., \& Margaryan, A. (2014). Technology-enhanced professional learning: Mapping out a new domain. In Littlejohn, A., \& Margaryan, A. (Eds.). Technology-enhanced professional learning: Processes, practices and tools (pp. 1-13). London: Routledge.

Littlejohn, A., \& Milligan, C. (2015). Designing MOOCs for professional learners: tools and patterns to encourage self-regulated learning. eLearning Papers, 42, 38-45.

Littlejohn, A., Hood, N., Milligan, C., \& Mustain, P. (2016). Learning in MOOCs, motivation and selfregulated learning. The Internet and Higher Education 29, 40-48. DOI: http://dx.doi.org/10.1016/j.iheduc.2015.12.003

Margaryan, A., Bianco, M., \& Littlejohn, A. (2015). Instructional quality of Massive Open Online Courses (MOOCs). Computers \& Education, 80, 77-83. DOI: http://dx.doi.org/10.1016/j.compedu.2014.08.005 
Milligan, C., Littlejohn, A., \& Margaryan, A. (2013). Patterns of engagement in connectivist MOOCs. Journal of Online Learning \& Teaching 9(2), 149-159.

Milligan, C., \& Littlejohn, A. (2014). Supporting professional learning in a massive open online course. International Review of Research in Open and Distance Learning 15(5), 197-213. DOI: http://dx.doi.org/10.19173/irrodl.v15i5.1855

Milligan, C., \& Littlejohn, A., (2016) How Health Professionals Regulate their Learning in Massive Open Online Courses. The Internet and Higher Education 31, 113-121Radford, A. W., Robles, J., Cataylo, S., Horn, L., Thornton, J., \& Whitfield, K. E. (2014). The employer potential of MOOCs: A mixed-methods study of human resource professionals' thinking on MOOCs. The International Review of Research in Open and Distance Learning, 15(5), 1-25.

Rhoads, R. A., Berdan, J., \& Toven-Lindsey, B. (2013). The open courseware movement in higher education: unmasking power and raising questions about the movement's democratic potential. Educational Theory 63(1), 87-109. DOI: http://dx.doi.org/10.1111/edth.12011

Salmon, G., Gregory, J., Lokuge Dona, K., \& Ross, B. (2015). Experiential online development for educators: The example of the Carpe Diem MOOC. British Journal of Educational Technology, 46(3), 542-556. DOI: http://dx.doi.org/10.1111/bjet.12256

Weller, M.J. (2014). MOOC completion rates DO matter [Blog post]. Retrieved from http://nogoodreason.typepad.co.uk/no good reason/2014/07/mooc-completion-rates-domatter.html

Wigfield, A., \& Eccles, J.S. (2000). Expectancy-value theory of achievement motivation. Contemporary Educational Psychology, 25(1), 68-81. DOI: http://dx.doi.org/10.1006/ceps.1999.1015

White, S., Davis, H., Dickens, K. P., Leon, M., \& Sanchez Vera, M. (2015). MOOCs: What motivates producers and participants. In S. Zvacek, M. Restivo, J. Uhomoibhi, \& M. Helfert (Eds.) Proceedings of the 6th International Conference on Computer Supported Education (pp. 99114). Heidelberg: Springer.

Zheng, S., Rosson, M. B., Shih, P. C., \& Carroll, J. M. (2015). Understanding student motivation, behaviors and perceptions in MOOCs. In Proceedings of the 18th ACM Conference on Computer Supported Cooperative Work \& Social Computing (pp. 1882-1895). ACM. doi: http://dx.doi.org/10.1145/2675133.2675217

\section{Athabasca University}

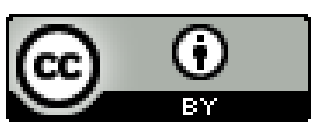

